\title{
FULFILLING THE POTENTIAL OF NUCLEAR POWER INDUSTRY THROUGH DEMAND SIDE MANAGEMENT
}

\author{
L.D. GITELMAN, L.M. GITELMAN \& M.V. KOZHEVNIKOV \\ Department of Energy and Industrial Management Systems, Ural Federal University, Russia.
}

\begin{abstract}
The study analyzes the feasibility and ways of including nuclear power plants (NPPs) in demand side management (DSM) programs. Reducing peak load on energy systems is of high interest to nuclear energy managers because the load grows and so does the share of base load, providing an impetus for the construction of new NPPs in regions. The authors propose the principles and mechanisms of DSM and a system of organizational and economic measures that would encourage energy companies to get actively engaged in DSM programs. It is shown that it is appropriate to consider DSM as a way of improving the flexibility characteristics of new NPPs, such as their increasing their capacity factor, boosting output while reducing costs and, therefore, increasing their profitability.

Keywords: cost, cost effectiveness, demand side management, reliability, load, nuclear power, flexibility.
\end{abstract}

\section{INTRODUCTION}

The problem of incorporating nuclear power plants (NPPs) in demand side management (DSM) schemes is particularly relevant to developing countries, where, according to the World Nuclear Association's (WNAs) Outlook 2030, most new nuclear reactors are planned to be built (Figs. 1 and 2), as well as to some European countries, for example, France and Belgium, where NPPs account for a significant share of generating capacity (Table 1).

One has to bear it in mind that the nuclear power dynamics is influenced by the refusal of some countries, such as Germany, to not only put into operation new capacities, but also their determination to decommission existing ones. Germany has the Act on the Peaceful Utilization of Atomic Energy and the Protection Against its Hazards [1] that was recently amended, now providing for a phase-out of NPPs now in operation with a total capacity of 18,569 MW by 2015-22. Nevertheless, nuclear power production has been growing at a relatively high pace, primarily driven by China $[2,3]$.

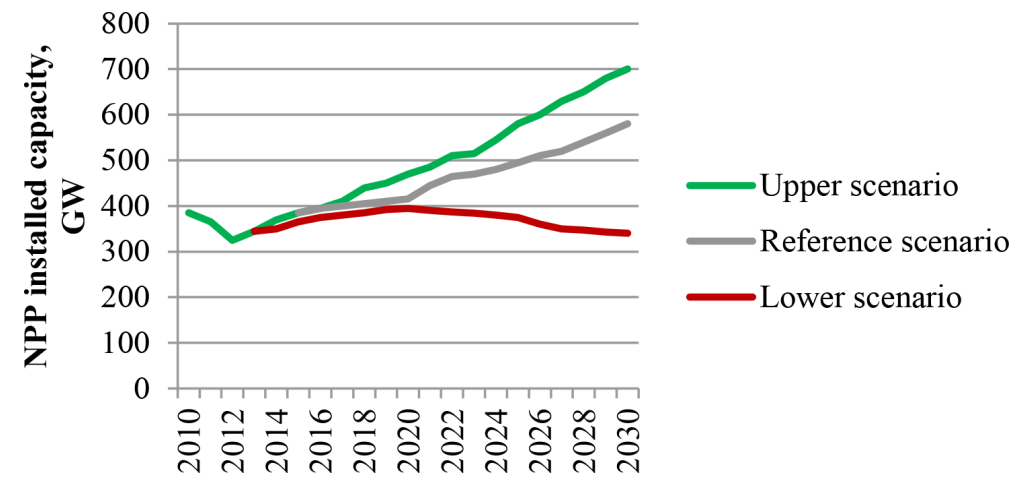

Figure 1: Three scenarios of nuclear power industry development through to 2030, according to the World Nuclear Association (WNA). 


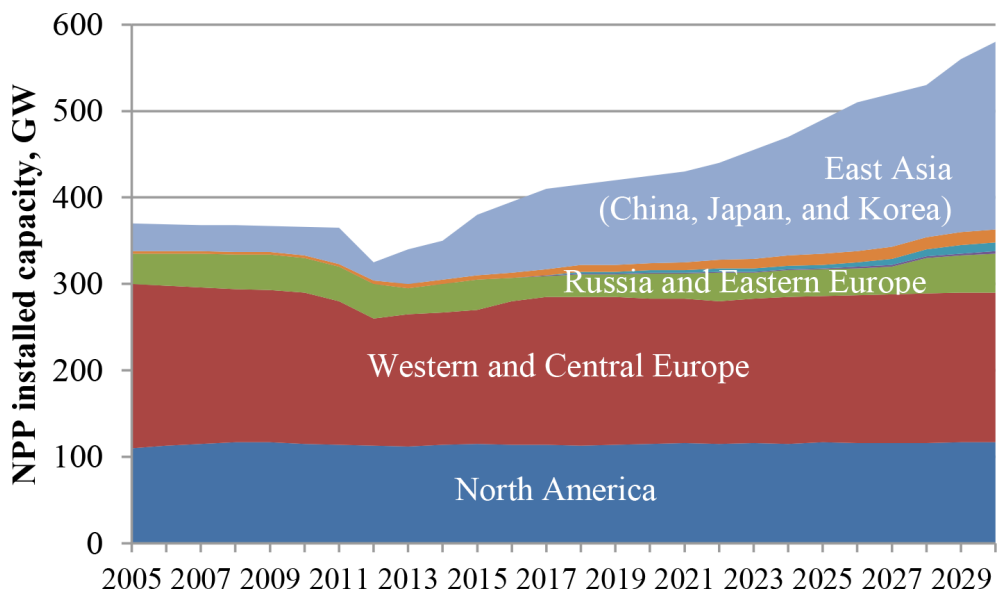

Figure 2: WNA Outlook 2030 for some regions under the upper scenario [5].

Table 1: European countries with large share of NPPs in generating capacity [6].

\begin{tabular}{|c|c|c|c|}
\hline \multirow{2}{*}{ Generation technology } & \multicolumn{3}{|c|}{ Installed capacity, MW } \\
\hline & France & Belgium & Germany \\
\hline Nuclear & 63,130 & 5,830 & 20,470 \\
\hline Hydro & 25,670 & 1,420 & 11,020 \\
\hline Oil & 13,240 & 1,340 & 5,860 \\
\hline Gas/Combined cycles & 7,500 & 5,990 & 21,810 \\
\hline Coal & 7,260 & 1,200 & 52,840 \\
\hline Wind & 6,080 & 912 & 27,160 \\
\hline Total & 122,880 & 16,680 & 127,140 \\
\hline
\end{tabular}

For developing countries the process is of major importance not only from the point of view of its economic effect that shows in reduced resource consumption and lower costs of power generation, but also because of its environmental outcome in the form of lower emissions [4]. Meanwhile, in Europe the integration of nuclear and renewable energy and traditional power generation methods (wind, hydropower, waste energy etc.) in DSM programs is used primarily for the purposes of long-term energy balance forecasting.

One example is a so-called dispatch and investment model for European electricity markets that pulls together data on the 13 most common electricity generation technologies in 27 countries of the European Union. The technologies are grouped by their energy efficiency and reliability characteristics. The model factors in detailed information on the installed capacity of power plants, their detailed technical specifications and expert views on the pace of development and trends for each technology. By linking these data to planned DSM 
activities it is possible to build an enlarged outlook for investment in new generating capacity. It makes sense to analyze nuclear power technologies within this model for two reasons: (1) NPP projects are extremely capital intensive; (2) the EU is gradually phasing out nuclear power due to high emergency risks [7, 8].

Studies conducted by the authors $[9,10]$ show the high effectiveness of NPPs' participation in DSM programs because, according to expert estimates, it helps reduce investments in the construction of new power plants by 8 to 10 percent. We shall take a closer look at the mechanism of such participation considering the technical and economic specifics of NPPs.

\section{CONDITIONS FOR EFFECTIVE FUNCTIONING OF NPPS: MODELS, PRICING, WHOLESALE MARKET POSITIONING}

1. In grids, NPPS should operate exclusively in a base load mode yielding the highest capacity factor, which is due to the unique energy and environmental efficiency of nuclear power units and higher per-unit investments when compared to thermal power generation plants. At the same time, the cost of electricity produced by existing NPPs is much lower than the cost of power generated by most thermal power generation plants.

2. The base load operation of NPPs within unified power generating systems calls for special flex capacity to cover peak and semi-peak loads. A highly efficient alternative to peakload plants could be found in load management implemented by vertically integrated and grid companies and electricity retailers by means of balancing the economic interests of contractors and customers.

This approach could bring about a significant reduction in capital and operating costs by disengaging some peak-load plants, helps boost the capacity factor of the NPP and improve the reliability of power supply at a relatively low cost, which, among other things, increases the financial stability of energy companies.

Reducing the peak load of energy supply systems is of high interest to nuclear power managers because a high of base load amid growing demand provides impetus to the construction of new NPPs in the region. Energy companies that operate major NPPs (such as AREVA, Mitsubishi, General Electric, Hitachi, Toshiba, Alstom, Cameco, Rosatom, USEC, URENCO, Shanghai Electric, etc.) could contribute to financing regional DSM programs that are designed by grid operators and retailers together with interested consumers [11-13].

3. NPPs should not participate in an organized spot market with marginal pricing and irregular generation modes of power plants because this is unadvisable from the technical and economic perspectives and leads to a disregard for price interests of consumers. NPPs may, however, enter into free two-sided contracts with major consumers who buy in the wholesale energy market, and with electricity retailers who seek to take advantage of the economic benefits that the nuclear power sector offers to its customers. The subject of contracts base load electricity that is supplied under the formula of fair price that is applied in its "soft" variant. Maximum deviations $(+,-)$ established by the regulator make this price negotiable. This enables end consumers of electricity generated by NPPs to get the price that matches the efficiency of these power units. One has to bear it in mind, though, that there is a high degree of uncertainty as regards the cost of electricity generated by NPPs being put into operation.

4. When an NPP operates as part of an energy system, there is a problem of valley filling (nighttime load drop). In some cases it could even require decreasing the capacity of the 
NPPs, which is undesirable due to abovementioned reasons. The capacity factor could be maximized during nighttime periods by using the following measures:

- Building peak load pumped storage power plants that are charged up at night during off-peak hours when power is cheap.

- Increasing industrial demand at night (additional shifts, rescheduling equipment maintenance to daytime; building up the output of equipment that operates at nighttime in the case of round-the-clock production cycles).

- Charging modern storage facilities of various types and applications (power and heat supply, electric vehicles, backup power for wind mills etc.) with energy generated by NPPs).

It has to be noted that nighttime valley filling is best ensured as part of organized demand-side management.

5. The flexibility of nuclear power units could be improved by launching small capacity NPPs that are technologically capable of operating safely under variable load (mid-peak) conditions and shutting down the capacity to a minimum at night hours, or shutting down completely on weekends. From the economic perspective, it is important to make sure that the unit costs of building such NPPs are lower than those of major base load power plants. The reason is that generally the cost of $1 \mathrm{kWh}$ of electricity generated by an NPP operated at a lower capacity factor will be higher than that of electricity generated by base load power plants operating at a maximum capacity factor. Reducing the cost of fixed capital and, consequently, fixed costs will help solve the problem to a certain extend. (In most cases, a lower capacity factor of smaller NPPs operating in a variable regime is unlikely to be offset fully by a cut in fixed costs). Among the measures that could be taken are simplified technological schemes and safety methods, cheaper construction materials and lower costs of construction and installation works.It has to be noted, though, that the proposed solution does not address the issue of meeting peak demand in energy systems, including by means of implementing DSM programs.

\section{PRINCIPLES OF DEMAND SIDE MANAGEMENT IN POWER ENGINEERING}

DSM refers to the targeted and systematic influence that energy companies exert on the volumes, structure and patters of energy consumption in the area of service. The companies in question are those operating in retail electricity markets: integrated and grid operators and retailers $[9,10,14,15]$.

It is important to note that improving the efficiency of electricity use and the development of the companies' generating (grid) capacities are viewed as complementary ways of ensuring the reliability of electricity supply. The saved energy became a supplementary resource that replaces production (transmission) at new installations. By pro-actively influencing demand for energy and capacity the energy company gets an opportunity to meet additional energy needs in any sector of the home region at minimum cost. The underlying principle of DSM is the alignment of interests of the energy company, consumers and the region (longterm public interests).

Energy companies can be motivated to employ DSM either by external factors or targeted incentives from regional regulators.

The prime tool to directly influence consumers is programs for managing demand for energy and capacity (Fig. 3). The composition of the set of such programs is determined by the goals of the energy company and the objects of management. Depending on the goals the following DSM programs are employed: 


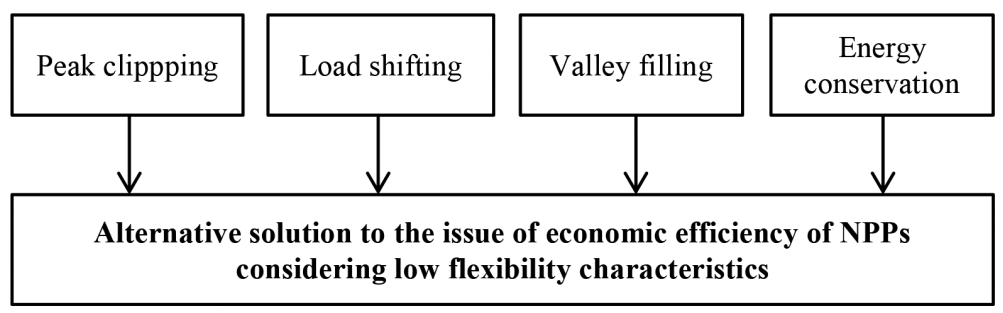

Figure 3: Targeted DSM programs in power engineering.

- Peak clipping.

- Valley filling.

- Load shifting (from peak to off-peak periods).

- Overall energy conservation.

Various forms and methods of encouraging energy efficiency and consumers' participation in regional energy conservation programs are used within the framework of DSM.Discounts off the price of energy saving equipment are offered by energy companies to both buyers and suppliers of energy efficient appliances in order to create supply and demand on the market. As a result, retail prices go down and the payback period of investments in new equipment is reduced to a level that is acceptable to the consumer. Discount rates are calculated by comparing investments in equipment and energy savings; they depend on the energy efficiency characteristics of the equipment in question.Direct investment includes the cost of equipment being installed for consumers, including devices and installations that are provided free of charge, such as electricity meters, controllers, high efficiency electric motors, energy saving lighting equipment and the like.Discounts off electricity tariffs are applied in load dispatch management programs and programs for the development of heat accumulator systems as discounts off electricity bills. The discounts are accounted for as annual costs of the programe and are taken into consideration with assessing its efficiency.Financing (consumer loans). This allowance is offered by the energy company to its consumers as part of several programs at a time. As the loans are paid back by consumers, the costs are separately accounted for in the program budget.

Bonuses for program participants. One-off bonuses are offered to consumers for signing up to and extended their agreement to participate in DSM programs. The bonuses are part of the capital costs of the program.

Bonuses for competition of a program. Such bonuses are offered by the energy company to program participants on the basis of the actual effect delivered by energy efficiency measures. Depending on the type of the program, the bonuses could be included in the program budget either as operating costs or as capital costs.

In many cases market incentives prove to be not enough to make energy companies start developing and implementing DSM programs. A special mechanism is therefore needed to encourage them to do so that should be enforced by energy sector regulators.

The proposed organizational and economic measures could be categorized as prescriptive, restrictive and rewarding ones.

1. Energy companies are required by law to develop and implement DSM programs in cooperation with consumers. Appropriate provisions should be made in federal and regional laws that set the rules for energy companies. 
2. Energy companies' requests for an electricity and heat tariff review that would result in a hike above the inflation rate must be considered by regulators only if there is a DSM program in place that is approved by consumers. If the program is not accomplished within the reporting period, the review request is automatically put on hold.

3. The energy company is entitled to apply special tariffs that have been negotiated with and approved by consumers that would promote energy efficiency and rational energy use patterns.

4. Regulatory authorities should set a higher rate of return on funds that energy companies invest in rational energy use.

Energy companies should be allowed to deduct a certain share of their expenditures on developing DSM programs from the total amount of corporate tax payable.

\section{CONCLUSION}

DSM programs being implemented by regional utilities should be viewed as an important promising factor that increases the commercial and public effectiveness of nuclear power. DSM can and should be considered as an alternative to increasing the flexibility of newly launched NPPs. For example, a dense and smooth schedule of load on the grid is of great interest to NPP managers because it enables them to improve the capacity factor of the power plant, increase output and bring down costs and ensure higher profitability even at lower selling prices. At the same time this gives a new impetus to the construction of new NPPs with optimized capacity, including those intended for replacing power plants that are slated for decommissioning.

Keeping the above mentioned in mind, it is worth working out and introducing mechanisms for including nuclear power facilities in the process of DSM. Developing countries are yet to deal with the problem of creating the regulatory and legal framework that would set the rules for all participants in DSM programs, determine the necessary institutional transformations and contain a rational combination of administrative enforcement methods and economic incentives for both energy companies and energy and capacity consumers.

It has to be remembered that there is a number of barriers preventing the development of the promising DSM format that is described in this article. One of them is that many companies do not have enough qualified experts among their energy managers who would be capable of making an accurate judgment on the effectiveness of energy saving innovations and, most importantly, on the technical, economic and production outcomes of measures aimed at rationalizing daily load curves, including the need for additional spending. Finally, there is also the traditional disbelief in everything the power supplier does, especially when it is a new and fuzzy service.

\section{ACKNOWLEDGEMENT}

The work was supported by Act 211 Government of the Russian Federation, contract № 02.A03.21.0006.

\section{REFERENCES}

[1] Act on the peaceful utilization of atomic energy and the protection against its hazards, [in German], available at: https://www.gesetze-im-internet.de/bundesrecht/atg/gesamt.pdf

[2] Nuclear Power by Country, available at: https://en.wikipedia.org/wiki/Nuclear_power_ by_country 
[3] World Nuclear Generation and Capacity, available at: http://www.nei.org/KnowledgeCenter/Nuclear-Statistics/World-Statistics/World-Nuclear-Generation-and-Capacity

[4] Implementing Energy Efficiency and Demand Side Management. South Africa's Standard Offer Model. Low Carbon Growth Country Studies Program, 2011, available at: https:// www.esmap.org/sites/esmap.org/files/ESMAP_StandardOffer_SouthAfrica_WebFinal.pdf

[5] The Global Nuclear Fuel Market: Supply and Demand 2013-2030, The World Nuclear Association: London, p. 248, 2013.

[6] Bergaentzle, C., Clastres, C. \& Khalfallah, H., Demand-side management and European environmental and energy goals: an optimal complementary approach. Energy Policy, Elsevier, 67, pp. 858-869, 2014.

http://dx.doi.org/10.1016/j.enpol.2013.12.008

[7] Paulus, M. \& Borggrefe, F., The potential of demand-side management in energy-intensive industries for electricity markets in Germany. Applied Energy, 88, pp. 432-441, 2011.

http://dx.doi.org/10.1016/j.apenergy.2010.03.017

[8] Zerrahn, A. \& Schill, W.-P., On the representation of demand-side management in power system models. Energy, 84, pp. 840-845, 2015.

http://dx.doi.org/10.1016/j.energy.2015.03.037

[9] Gitelman, L.D., Ratnikov, B.E. \& Kozhevnikov M.V., Demand-side management for energy. A unique innovation for the Russian power industry, [in Russian], Ekonomika: Moscow, p. 118, 2013.

[10] Gitelman, L.D., Ratnikov, B.E. \& Kozhevnikov M.V., Demand-side management for energy in the region. Economy of Region, 2, pp. 78-84, 2013.

[11] Nuclear Technology Review 2015, available at: https://www.iaea.org/About/Policy/ GC/GC59/GC59InfDocuments/English/gc59inf-2_en.pdf

[12] The Future of Nuclear Power. An Interdisciplinary MIT Study, 2003, available at: http:// web.mit.edu/nuclearpower/pdf/nuclearpower-full.pdf

[13] Schneider, M., Froggatt, A., Hazemann, J., Katsuta, T., Ramana, M.V. \& Thomas, S., The World Nuclear Industry. Status Report 2015. Paris, London, 2015, available at: https:// wisenederland.nl/sites/default/files/images/WNISR2015.pdf

[14] Sidorovskaya, N., Demand-side management in the global electricity market, [in Russian]. Energy Market, 7(132), pp. 28-34, 2015.

[15] Martushev, S., Diversification of financial resources as a factor of the Russian nuclear industry competitiveness, [in Russian], available at: http://www.rcb.ru/rcb/2009-16/26305/ 